\title{
Copolymerization of Styrene with Isobutyl Vinyl Ether by Radiation
}

\author{
Kanae Hayashi, Koichiro Hayashi, and Seizo OKamura \\ Osaka Laboratory for Radiation Chemistry, Japan Atomic Energy \\ Research Institute, 508, Mii, Neyagawa, Osaka, Japan.
}

(Received August 7, 1972)

\begin{abstract}
In order to elucidate the reason for the considerable difference in the activation energies for the propagation of styrene and isobutyl vinyl ether (IBVE), radiation-induced copolymerization of styrene with IBVE was carried out in bulk at 0 and $40^{\circ} \mathrm{C}$. The obtained copolymerization ratios are $\left(\mathrm{M}_{1}=\right.$ styrene $)$

$$
\begin{array}{rll}
0^{\circ} \mathrm{C} & r_{1}=0.46 \pm 0.05, & r_{2}=9 \pm 1 \\
40^{\circ} \mathrm{C} & r_{1}=0.20 \pm 0.06, & r_{2}=11 \pm 3
\end{array}
$$

From the temperature dependences of $r_{1}$ and $r_{2}$, mutual polymerization rate constants, $k_{12}$ and $k_{21}$, and their activation energies, $E_{\mathrm{p}}$ were evaluated assuming both $k_{\mathrm{p}}$ and $E_{\mathrm{p}}$ values obtained in bulk polymerizations of styrene and IBVE are constant also in the copolymerization systems studied. It is found that in the reactivity of cation, styrene is greater than IBVE, however, the relation is reversed in relative reactivity of monomer.

From the comparison with $E_{\mathrm{p}}$ values in other free cationic polymerization systems, $E_{\mathrm{p}}$ value for IBVE cation is considered to be in some respects extraordinary high, as well as its frequency factor. This is presumably explained in terms of the solvation of IBVE to cation and possibly, resonance stabilization of IBVE cation end.

KEY WORDS Cationic Copolymerization / Radiation / Styrene /

Isobutyl Vinyl Ether / Monomer Reactivity Ratio / Propagation /
\end{abstract}

Previous investigations have been carried out in order to estimate the propagation rate constants, $k_{\mathrm{p}}$ and the activation energies, $E_{\mathrm{p}}$ in the free-cationic polymerizations of bulk styrene ${ }^{1}$ and isobutyl vinyl ether $(\mathrm{IBVE})^{2}$ which were initiated by radiation. In the case of styrene, it was found that $k_{\mathrm{p}}$ in free-cationic polymerization was the largest and $E_{\mathrm{p}}$ was the smallest in comparison with those values with other mechanisms. And so, it is easily understood that the large $k_{\mathrm{p}}$ value obtained $\left(2.4 \times 10^{6} l\right.$ $\mathrm{mol}^{-1} \mathrm{sec}^{-1}$ at $25^{\circ} \mathrm{C}$ ) is attributable to low $E_{\mathrm{p}}$ value as well as to high frequency factor, $A_{\mathrm{p}}$. However, in IBVE, the also relatively large $k_{\mathrm{p}}$ $\left(1.2 \times 10^{5} l \mathrm{~mol}^{-1} \mathrm{sec}^{-1}\right.$ at $\left.25^{\circ} \mathrm{C}\right)$ is considered to be due to the extraordinarily large $A_{\mathrm{p}}$ value in spite of large $E_{\mathrm{p}}$ value, as compared to those in styrene. In a bulk polymerization of isopropyl vinyl ether by radiation, Stannett ${ }^{3}$ has indicated an apparent energy of activation for the polymerization rate, which is probably not much different from $E_{\mathrm{p}}$, as $7.4 \mathrm{kcal} \mathrm{mol}^{-1}$.
These activation energies give an indication that a high $E_{\mathrm{p}}$ is a general trend in vinyl ethers. In this work the copolymerization between styrene and IBVE has been studied to elucidate the reason for the contrasting behaviors of the propagation steps of styrene to that of IBVE.

No other work than Ueno's ${ }^{4}$ has been reported concerning the copolymerization studies with a free-cationic mechanism. He had determined copolymerization ratios in styrene- $\alpha$-methylstyrene and styrene-IBVE systems to demonstrate the predominance of a free-cationic mechanism in the polymerization of styrene by radiation. On the other hand, using catalysts, Masuda and Higashimura ${ }^{5-7}$ have made detailed studies on the cationic copolymerization between styrene derivatives and vinyl ethers by varying the solvent and/or temperature. As a free-cationic polymerization is an extreme situation of the pair-cationic one, such a comparison of the copolymerization behaviors must be quite significant for understanding the features of the 
free-cationic polymerization.

\section{EXPERIMENTAL}

Purification procedures of monomers is described elsewhere. ${ }^{1,2}$ Silica gel and barium oxide were used as drying agents for styrene and IBVE, respectively.

A sampling system is shown in Figure 1. A and $\mathrm{B}$ denote well-dried monomers, i.e., styrene and IBVE, respectively. Each sample tube containing the monomer connects to volumecalibrated sampling tubes, $\mathrm{C} 1-\mathrm{C} 6$ through a magnet operated valve D1 (or D2). At first, the whole system was evacuated for two days with heating the sampling tubes and baking out of the remaining part other than the two monomer tubes, and sealed off at the constriction G. Then the frozen monomer was evacuated by breaking the break seal, F1 (or F2) and sealed off at the constriction, $\mathrm{H} 1$ (or $\mathrm{H} 2$ ). A required volume of styrene was introduced into a sampling tube, for example $\mathrm{C} 1$, by breaking the break seal E1 and opening the valve D1. After the valve D1 was closed, IBVE was introduced by breaking the break seal E2 and opening the valve D2, and the ampoule C1 was sealed off at the constriction J1. Through similar procedures, the copolymerization samples of different styrene composition were prepared.

Irradiations were carried out by ${ }^{60} \mathrm{Co} \gamma$-rays at a dose rate of $7.7 \times 10^{4} \mathrm{r} / \mathrm{hr}$. The obtained

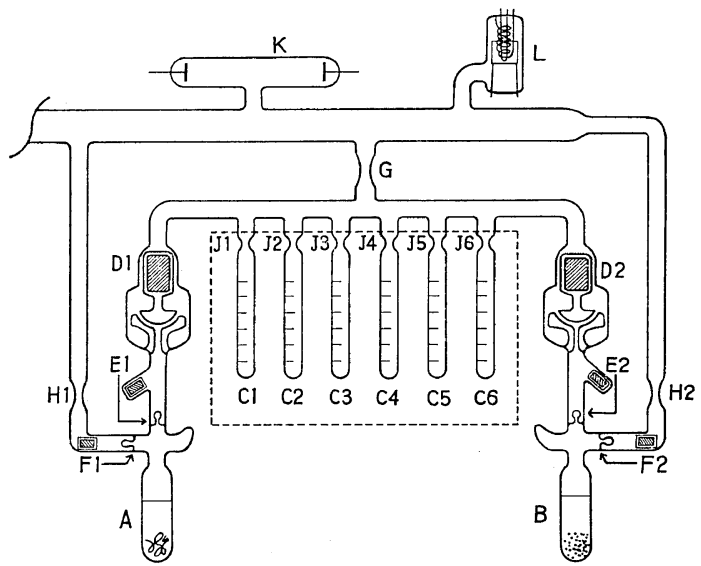

Figure 1. Vacuum system for the preparation of copolymerization samples. polymer yields were always maintained at a level of less than $2 \%$. The obtained monomerpolymer mixture was evacuated to remove the unreacted monomers and dried at $60^{\circ} \mathrm{C}$ for more than two days. The polymer compositions were determined by the elementary analysis using a Yanaco CNH-corder type MT-2.

Viscosity measurements were carried out in benzene solution at $30^{\circ} \mathrm{C}$.

\section{RESULTS}

It is well known that styrene polymerizes via a radical, cationic or anionic mechanism, while IBVE polymerizes via a radical or cationic mechanism. However in radical mechanisms, the reactivity of IBVE is very poor ${ }^{8}$ and the formation of IBVE-rich copolymer seems to exclude the possibility of radical copolymerization.

The intrinsic viscosity of polymers obtained in copolymerization systems at $0^{\circ} \mathrm{C}$ is shown in Figure 2 as a function of styrene fraction in the polymer. For the purpose of comparison, viscosities of the polymer mixtures, composed from polystyrene and poly(IBVE), both of which are obtained in homopolymerizations at $0^{\circ} \mathrm{C}$ are also given in Figure 2. It is apparent that the polymer viscosity decreases considerably in copolymerization systems, which is generally observed in pair-cationic polymerization. ${ }^{5}$ Examination of infrared absorption spectra failed to give a significant evidence for copolymer formation but the band at $700 \mathrm{~cm}^{-1}$ due to the vibration of phenyl group seemed to be nar-

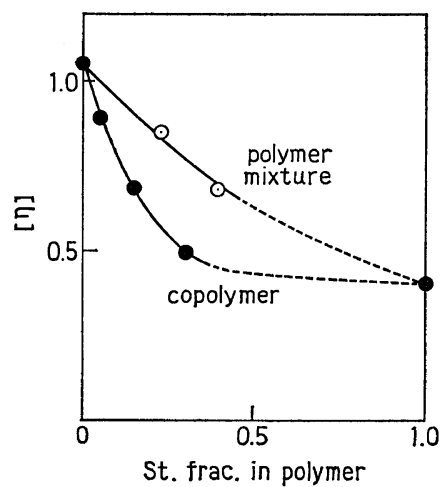

Figure 2. Intrinsic viscosity $v s$. styrene fraction in copolymer and polymer mixture. 
rower in copolymer than in polystyrene.

Copolymerization in bulk state was carried out at 0 and $40^{\circ} \mathrm{C}$. Almost all of the obtained polymers were sticky because of their high IBVE contents. As shown in Figure 3, it was found that a relatively larger amount of IBVE incorporated into the copolymer than its initial monomer composition and the IBVE content of the copolymer increased with increasing polymerization temperature. In the sense of cationic copolymerization initiated by catalyst, the formation of styrene-IBVE copolymer with a considerable amount of styrene is striking since the reactivity of IBVE has been estimated to be $40-60$ times greater than that of styrene. $^{9}$ The monomer reactivity ratios obtained are

$$
\begin{array}{rll}
0^{\circ} \mathrm{C} & r_{1}=0.46 \pm 0.06, & r_{2}=9 \pm 1 \\
40^{\circ} \mathrm{C} & r_{1}=0.20 \pm 0.06, & r_{2}=11 \pm 3
\end{array}
$$

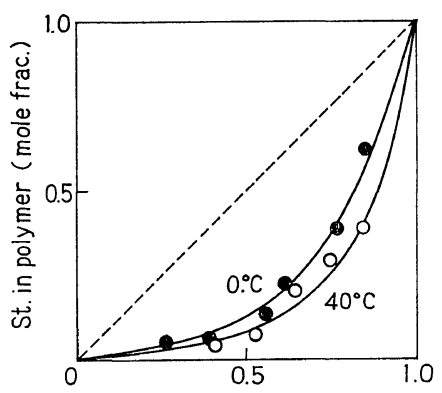

St. in monomer (mole frac.)

Figure 3. Copolymer composition curves at 0 and $40^{\circ} \mathrm{C}$.

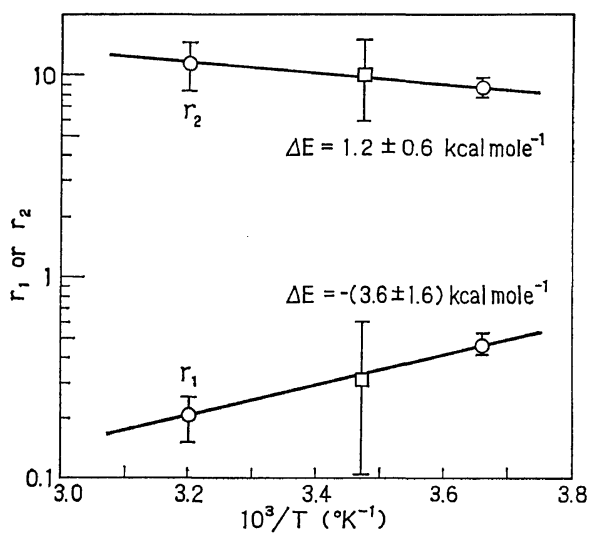

Figure 4. Temperature dependence of $r_{1}$ and $r_{2}$ values: $\bigcirc$, present study; $\square$, Ueno's work ${ }^{3}$. where $M_{1}$ is styrene.

The value obtained here agree well with those reported by Ueno, et al., ${ }^{4}\left(r_{1}=0.3 \pm 0.3\right.$, $r_{2}=10.0 \pm 4.0$ at $15^{\circ} \mathrm{C}$ ) when the temperature dependence of $r_{1}$ and $r_{2}$ values is taken into account as shown in Figure 4. The obtained temperature coefficients are $-(3.6 \pm 1.6)$, and $1.2 \pm 0.6 \mathrm{kcal} \mathrm{mol}^{-1}$ for $r_{1}$ and $r_{2}$, respectively.

\section{DISCUSSION}

Generally, a copolymerization study is carried out in a dilute solution for the purpose of keeping the bulk properties of polymerization system independent of the influence of monomer-composition variations. In this study, though bulk copolymerization has been carried out, the obtained results are believed to be essentially not much different from those in nonpolar solvents for the reasons given below.

In several cationic polymerization systems initiated by catalysts, it has been proposed that a selective solvation of the propagating end by polar monomer took place in a nonpolar solvent. ${ }^{4,6,10}$ Such a solvation will be more probable in a free-cationic polymerization since the electric field around the propagating ion must be considerably stronger than that in the case of an ion pair. If IBVE molecules preferentially solvate the ion, the ionic atmosphere around the cation may be regarded approximately the same as that in solution copolymerization in nonpolar solvent, and in this case, the difference in the bulk polarity is less significant. On the other hand, if there were to be no preferential solvation, the bulk polarity became operative although the difference in dielectric constants in styrene (2.4) and IBVE (3.4) is not so large.

However if there exists a selective solvation by IBVE, it is likely that $k_{\mathrm{p}}$ and $E_{\mathrm{p}}$ values in the propagation of styryl cation with styrene are influenced by the presence of IBVE in the system. In the reaction under consideration, the nearest position to a propagating cation is probably occupied by a styrene molecule which is going to be in the transition state for the addition and therefore a possible consequence may not be so serious. In any case, on the basis of $k_{\mathrm{p}}$ and $E_{\mathrm{p}}$ values estimated in the homopolymerization of styrene ${ }^{1}$ and IBVE, ${ }^{2} k_{\mathrm{p}}$ 
Ka. Hayashi, Ko. Hayashi, and S. OKamura

Table I. Characteristic values in free-cationic propagation reactions

\begin{tabular}{llccr}
\hline Reaction & $\begin{array}{c}k_{\mathrm{p}}\left(0^{\circ} \mathrm{C}\right), \\
\mathrm{mol}^{-1} \mathrm{Sec}^{-1}\end{array}$ & $\begin{array}{c}E_{\mathrm{p}}, \\
\text { kcal mol-1 }\end{array}$ & $\log A_{\mathrm{p}}$ \\
\hline $1^{\mathrm{a}}$ & $\mathrm{St}^{+}+\mathrm{St}$ & $(1.7 \pm 1.1) \times 10^{6}$ & $2.2 \pm 1.3$ & $8.0 \pm 1.1$ \\
2 & $\mathrm{St}^{+}+\mathrm{IBVE}$ & $(3.7 \pm 2.0) \times 10^{6}$ & $5.8 \pm 2.9$ & $11.2 \pm 2.6$ \\
3 & $\mathrm{IBVE}^{+}+\mathrm{St}$ & $(4.2 \pm 1.1) \times 10^{3}$ & $8.4 \pm 3.4$ & $10.4 \pm 2.9$ \\
$4^{\mathrm{b}}$ & IBVE $^{+}+\mathrm{IBVE}$ & $(3.8 \pm 1.4) \times 10^{4}$ & $9.6 \pm 2.8$ & $12.3 \pm 2.2$ \\
\hline
\end{tabular}

a $\operatorname{Ref} 1$.

b Ref 2 .

at $0^{\circ} \mathrm{C}, E_{\mathrm{p}}$ and $\log A_{\mathrm{p}}$ values for mutual propagation reactions are evaluated as given in Table I. Although the each estimation error, evaluated as a maximum limit, is relatively large, it is evident that there are clear differences in $k_{\mathrm{p}}$ and $E_{\mathrm{p}}$ values in the four kinds of propagation reactions. Taking into account each temperature coefficient, $k_{\mathrm{p}}$ values between 0 and $50^{\circ} \mathrm{C}$ are in the following order

$$
k_{12}>k_{11}>k_{22}>k_{21}
$$

That is to say, the reactivities of propagating cations and monomers are

$$
\begin{aligned}
& \mathrm{St}^{+} \gg \mathrm{IBVE}^{+} \\
& \mathrm{St}<\mathrm{IBVE} .
\end{aligned}
$$

The relative reactivity of propagating species is in the reverse order of the monomer's which is common in radical polymerization. ${ }^{11}$ It was previously reported that $E_{\mathrm{p}}$ in $\mathrm{IBVE}^{2}$ was considerably large compared with that of styrene ${ }^{1}$ and in the present study, it was found that $E_{\mathrm{p}}$ values in mutual propagation reactions were between the $E_{\mathrm{p}}$ values of the homopolymerizations. $A_{\mathrm{p}}$ in IBVE is far greater than that in styrene and the $A_{\mathrm{p}}$ values in cross propagation reactions are also between the two values.

In pair-cationic polymerization, the reactivity of IBVE is too large as compared to that of styrene such that a copolymerization study between these monomers is almost impossible. Subsequently, Masuda and Higashimura ${ }^{5-7}$ have carried out the copolymerization of styrene derivatives such as $\alpha$ - and $p$-methylstyrene or $p$-methoxystyrene with 2-chloroethyl vinyl ether. It was found that the fraction of the styrene derivative in the polymer increased with the use of a strong catalyst and/or polar solvent. ${ }^{5,7}$ The fact that styrene-IBVE copolymer was formed in a free-cationic polymerization shows a good correspondence with the above finding when, as described in early part, the exceedingly higher reactivity of IBVE over styrene in the case of ion pair was taken into account. It was also found that, as was in this study, $r_{1}$ decreased and $r_{2}$ increased with increasing polymerization temperature, while in the copolymerization between styrene derivatives or vinyl ethers $r_{1}$ and $r_{2}$ hardly depend on temperature. ${ }^{6}$ From these correspondences in copolymerization behaviors in both mechanisms, it is enough to say that the free-ionic polymerization is an extreme case of pair-ionic one, where the dissociation of the catalyst is almost complete.

It has been pointed out that vinyl ethers show several contrasting behaviors in comparison to those of other vinyl monomers as styrene homologues in the fields of pair-cationic polymerization. ${ }^{12}$ The copolymerization behaviors described above, along with high $E_{\mathrm{p}}$ values in vinyl ethers, ${ }^{2,3}$ also give an indication that the propagation mechanisms in styrene and vinyl ether homologues are somewhat different from each other in free-cationic polymerization as well as in pair-cationic case. In the gas phase, the attachment of positive ions with thermal energy to an olefin is known to take place with sufficient reaction rates ${ }^{13}$ and the situation may be similar also in liquid system when solvation of ion is disregarded. In the radiation-induced polymerization of bulk isobutylene, ${ }^{14} E_{\mathrm{p}}$ was. found to be $2 \mathrm{kcal} \mathrm{mol}^{-1}$, which showed a fair coincidence with the value in styrene. ${ }^{1}$ These facts suggest that the energy requirement in free-ionic polymerization of vinyl monomers is generally low in nonpolar systems.

Using Eyring's rate expression in solution, ${ }^{15}$. the activation entropy, $\Delta S^{\neq}$for the free-cationic 


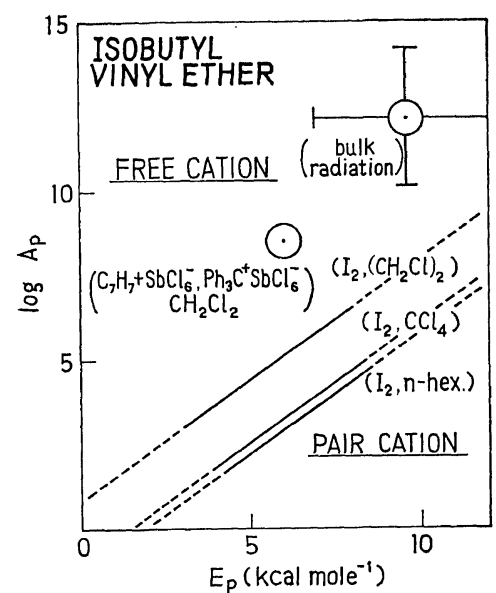

Figure 5. Relationship between $\log A_{\mathrm{p}}$ and $E_{\mathrm{p}}$ in the polymerization of IBVE.

polymerization in bulk state was calculated to be $-24 \pm 8$ and $-4 \pm 10$ e.u. for styrene and IBVE, respectively. The $\Delta S \neq$ for styrene shows respectively close agreement with the value expected from the Pepper's formula, ${ }^{16}$

$$
\Delta S^{\neq}=-28+\Delta S^{\neq} \text {(solv.), }
$$

proposed for the solution polymerization, however $\Delta S^{\neq}$for IBVE is apparently extraordinarily large.

Then, consider the propagation mechanism of IBVE. In Figure 5, the relationship between $E_{\mathrm{p}}$ and $A_{\mathrm{p}}$ in several systems of IBVE polymerization are illustrated. Kanoh's results ${ }^{17,18}$ in a few solvents indicates that there is an increase of $k_{\mathrm{p}}$ in a polar solvent and this can be explained in terms of the dissociation process of the ion pair in the transition state of propagation, when a weak catalyst as iodine is used. Recently, Bawn, et al. ${ }^{19}$ have reported the polymerization of IBVE in 1,2-dichloroethane using tropylium hexachloroantimonates and triphenyl methyl tetrafluoroborate which completely dissociate to form free ions at a sufficiently low concentration. They determined $k_{\mathrm{p}}$ and $E_{\mathrm{p}}$ values of $5 \times 10^{3} l \mathrm{~mol}^{-1} \mathrm{sec}^{-1}$ at $0^{\circ} \mathrm{C}$

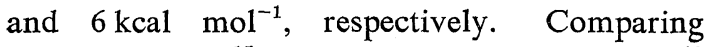
Kanoh's result ${ }^{17}$ in $\left(\mathrm{CH}_{2} \mathrm{Cl}\right)_{2}$ with Bawn's, ${ }^{19}$ shows the difference in pair-cationic and freecationic polymerization of IBVE in relatively polar solvents. The increase of $k_{\mathrm{p}}$ is considered as being mainly due to the enhancement of $A_{\mathrm{p}}$ with the use of strong catalyst. On the other hand, when the results in bulk polymerization ${ }^{2}$ are compared with Bawn's, the effect of the solvent in free-cationic propagation of IBVE is indicated. Apparently, the use of polar solvent seems to decrease both $E_{\mathrm{p}}$ and $A_{\mathrm{p}}$ values considerably.

Above all it can be said that the bulk polymerization of alkyl vinyl ethers via a freecationic mechanism is characterized by high $E_{\mathrm{p}}$ and $A_{p}$ values. The probable reason for this is the solvation of vinyl ether molecules to the ion can be raised as has been suggested in paircationic polymerization., ${ }^{4,6}$ Solvation phenomena should be separately considered in terms of long-range and short-range interactions. The magnitude of long-range solvation interactions may be well discussed in terms of the static dielectric constant of the medium and the solvation energy in $\left(\mathrm{CH}_{2} \mathrm{Cl}\right)_{2}$ must be greater than that in IBVE. However the solvation of the propagating ion due to the contribution of the short-range interactions is quite complicated being reflected by the structure and the orientation of solvent molecules around the cation. It seems quite natural to presume the coordination of an electronegative oxygen to a cation. A high solvating power of vinyl ether homologue was proved in the $\pi$-complex formation of vinyl monomers with iodine. ${ }^{20}$ It was proposed through the quantum mechanical calculation that in the polymerization of vinyl ethers, the oxygen atom coordinates with the propagating cation as well as double bond does, to form a four centered transition state complex. ${ }^{21}$ Accordingly it may be probable that IBVE greatly stabilizes the propagating cation by orienting the oxygen atom to the cation and the total solvation energy in IBVE is greater that in $\left(\mathrm{CH}_{2} \mathrm{Cl}\right)_{2}$. If so, the selective solvation by IBVE may be likely.

Another probable reason for high $E_{\mathrm{p}}$ value vinyl ether is a reasonance stabilization of the propagating cation as described below ${ }^{19,22}$

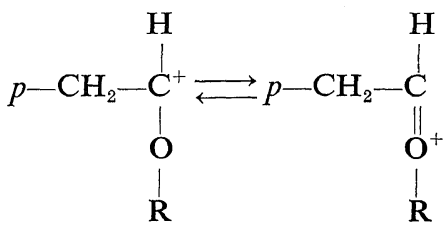


Through theoretical calculations, ${ }^{22}$ it has been pointed out that the reactivity of vinyl ethers could be well explained on the basis of the resonance structure of such a cation. Actually, solvation of a propagating cation end with vinyl ether molecules and resonance stabilization of vinyl ether cation end are probably phenomena not independent of each other. The solvation of the propagating cation will exert influence on the resonance and make a change in the charge distribution of the cation, probably which favors polymerization. Coordination of monomer to the propagating cation will also influence the reactivity of the monomer as that of the cation.

In any event, a consideration of these two probable processes is sufficient to explain the relative magnitudes of $E_{\mathrm{p}}$ values in Table I. In addition to the conventional $E_{\mathrm{p}}$ value in a nonpolar system, e.g., $2 \mathrm{kcal} \mathrm{mol}^{-1}$, the solvation energy of the cation end must be considered in reaction 2; on the other hand in reaction 3 , the resonance stabilization energy should be taken into account. In reaction 4, both processes are also operative.

High $A_{\mathrm{p}}$ values are also characteristic in the bulk polymerization of vinyl ethers as compared to that of styrene. The fact that $A_{\mathrm{p}}$ values in reactions 2 and 3 are considerably greater than $A_{\mathrm{p}}$ in the homopolymerization of styrene suggests a different transition structure in the propagation process of IBVE. In the homopolymerization of vinyl ether, it is rather likely to presume a five centered coordination between the $\alpha$ carbon and oxygen of the propagating ion, $\alpha, \beta$, carbon and oxygen of the monomer when the resonance structure of $\mathrm{VE}^{+}$ and solvation of monomer are taken into account.

In this discussion, it has been tentatively proposed that the temperature coefficient of vinyl polymerization via a free-cationic mechanism is generally low in a nonpolar system and $E_{\mathrm{p}}$ becomes higher in polar solvents because of the solvation of the propagating cation. In this respect, the propagation mechanism is somewhat different in vinyl ethers probable because of the resonance in the propagating end and solvation of the monomer. Here it should be noted that the conclusions stated above rely on the premise of the preferential solvation with IBVE. However, if it were not for such solvation, which indicates only a small difference between the two monomers as a solvent for ion, the higher $E_{\mathrm{p}}$ 's in $\mathrm{p}^{+}+$IBVE reactions with respect to those in $\mathrm{p}^{+}+$St reaction must be given an alternative explanation. Effects of the solvent on a free-cationic propagation is one of the most essential problems which remains for future investigations.

Acknowledgments. The authors are grateful to Professor T. Higashimura and Dr. Y. Imanishi of Kyoto University for valuable discussions.

\section{REFERENCES}

1. Ka. Hayashi, Ko. Hayashi, and S. Okamura, Polymer J., 4, 426 (1973).

2. Ka. Hayashi, Ko. Hayashi, and S. Okamura, J. Polym. Sci. Part A-1, 9, 2305 (1971).

3. J. Kohler and V. Stannett, ACS-Polymer Preprints, 12, 98 (1971).

4. K. Ueno, Ko. Hayashi, and S. Okamura, Polymer, 7, 431 (1966).

5. T. Masuda, T. Higashimura, and S. Okamura, Polymer J., 1, 19 (1970).

6. T. Masuda and T. Higashimura, ibid. 2, 101 (1971).

7. T. Masuda and T. Higashimura, J. Macromol. Sci.-Chem., A5, 549 (1971).

8. G. E. Schildknecht, "Vinyl and Related Polymers," John Wiley \& Sons, Inc., New York, N.Y., 1952, p 593.

9. T. Higashimura, "Ionic Copolymerization Reactions," Modern Industrial Chemistry Series, No. 16, Asakura, Tokyo, 1967, p 233.

10. C. G. Overberger and V. G. Kamath, J. Amer Chem. Soc., 85, 446 (1963).

11. P. J. Flory, "Principles of Polymer Chemistry," Cornell University Press, Ithaca, N.Y. 1953, p 194.

12. T. Higashimura in "Structure and Mechanism in Vinyl Polymerization," T. Tsuruta and K. F. O'driscoll, Ed., Dekker, New York, N.Y., 1969, p 335.

13. F. H. Field, J. J. Franklin, and F. W. Lampe, J. Amer Chem. Soc., 79, 2419 (1957).

14. R. B. Taylor and F. Williams, ibid., 91, 3728 (1969).

15. S. Glasstone, K. J. Laider, and H. Eyring, "The Theory of Rate Process," McGraw Hill, 


\section{Copolymerization of Styrene with Isobutyl Vinyl Ether by Radiation}

New York, N.Y., 1941, p 199.

16. D. C. Pepper and P. J. Reilly, Proc. Roy. Soc. (London), A291, 41 (1966).

17. S. Okamura, N. Kanoh, and T. Higashimura, Makromol. Chem. 47, 35 (1961).

18. T. Higashimura and N. Kanoh, Kobunshi Kagaku (Chem. High Polymers), 23, 114 (1966).

19. C. E. H. Bawn, C. Fitzsimmons, A Ledwith, J. Penfold, D. C. Sherrington, and J.A. Weightman, Polymer, 12, 119 (1971).
20. N. Kanoh, K. Ikeda, A. Gotoh, T. Higashimura, and S. Okamura, Makromol. Chem., 86, 200 (1965).

21. T. Higashimura, T. Masuda, S. Okamura, and T. Yonezawa, J. Polym. Sci., Part A-1, 7, 3129 (1969).

22. T. Higashimura, N. Kanoh, T. Yonezawa, K. Fukui, and S. Okamura, Nihon Kagaku Zasshi (J. Chem. Soc. Japan, Pure Chem. Sect.), 81, 550 (1960). 